Ciência Florestal, Santa Maria, v. 26, n. 1, p. 171-179, jan.-mar., 2016

ISSN 0103-9954

\title{
EVOLUÇÃO ESTRUTURAL DE BRACATINGAIS DA REGIÃO METROPOLITANA DE CURITIBA, PARANÁ, BRASIL
}

\author{
STRUCTURAL EVOLUTION OF BRACATINGA STANDS IN CURITIBA METROPOLITAN \\ REGION, PARANÁ, BRAZIL
}

\author{
Luis Cesar Rodrigues da Silva ${ }^{1}$ Sebastião do Amaral Machado ${ }^{2}$ Franklin Galvão ${ }^{3}$ \\ Afonso Figueiredo Filho ${ }^{4}$
}

\begin{abstract}
RESUMO
O objetivo deste trabalho foi estudar a evolução estrutural de espécies arbóreas em bracatingais, ao longo de vinte anos. A bracatinga (Mimosa scabrella Benth.) é a espécie pioneira, de vida curta, que caracteriza os bracatingais. Sob as bracatingas forma-se um sub-bosque com outras espécies arbóreas, que vai assumindo o lugar da bracatinga com o passar dos anos e que é tratado como se fosse lenha da própria bracatinga, quando a área é cortada a cada 7 anos e a regeneração da bracatinga é novamente induzida com o uso do fogo. O processo de sucessão em bracatingais ainda não foi estudado e é útil identificar a idade em que as demais espécies passam a dominar o bracatingal. Trabalhou-se com 320 parcelas, distribuídas em bracatingais com idades variando de 3 a 20 anos, medidas entre 1998 e 2011. Foram medidos os DAP (diâmetro a altura do peito) e altura total de todas as espécies com DAP $\geq 5 \mathrm{~cm}$. Observou-se que, aos 11 anos, o conjunto das espécies supera a bracatinga em número de indivíduos e aos 19 anos as espécies arbóreas já apresentam uma distribuição diamétrica semelhante ao de uma floresta em fase mais avançada. De forma geral observou-se que, após os 10 anos de idade, um bracatingal já começa a tomar forma de um capoeirão.
\end{abstract}

Palavras-chave: distribuição diamétrica; dinâmica vegetal; Mimosa scabrella,

\section{ABSTRACT}

The objective of this research was to study the structural evolution of tree species in stands of bracatinga, along twenty years. The bracatinga (Mimosa scabrella Bentham) is a short-lived pioneer species that characterizes its stands. Under the bracatingas it is formed an understory with other tree species which will replace bracatinga over the years and it is too treated as if it were bracatinga's firewood, when the area is submitted to clear cutting at every 7 years and bracatinga regeneration is again induced by burning the area. The succession process in stands of bracatinga has not been studied yet and is useful to identify the age when other trees species dominate the stands. The data for this research came from 320 sample plots measured between 1998 and 2011, distributed in stands of bracatinga aged 3 to 20 years. The DBH (diameter at breast height) and total height of all species with a $\mathrm{DBH} \geq 5 \mathrm{~cm}$ were measured. It was observed that, at age 11, the set of others species outnumber bracatinga. At age 19 tree species already have a diameter distribution similar to that one of a forest in a more advanced stage. Generally speaking it was observed that after

1 Engenheiro Florestal, Mestrando em Engenharia Florestal, Universidade Federal do Paraná, Campus III, Av. Pref. Lothário Meissner, 900, CEP 80210-170, Jardim Botânico, Curitiba (PR), Brasil. Bolsista do CNPq. luisnabravo@gmail.com

2 Engenheiro Florestal, PhD, Professor Sênior do curso de Pós-graduação em Engenharia Florestal, Universidade Federal do Paraná, Campus III, Av. Pref. Lothário Meissner, 900, CEP 80210-170, Jardim Botânico, Curitiba (PR), Brasil. Bolsista de produtividade do CNPq.samachado@ufpr.br

3 Engenheiro Florestal, Dr., Professor Associado IV do Curso de Pós-Graduação em Engenharia Florestal, Universidade Federal do Paraná, campus III, Av. Pref. Lothário Meissner, 900, CEP 80210-170, Jardim Botânico, Curitiba (PR), Brasil. fgalvao@ufpr.br

4 Engenheiro Florestal, Dr., Professor Associado do Departamento de Engenharia Florestal da Universidade Estadual do Centro-Oeste, PR-153, KM 7, Bairro Riozinho, CEP 84500-000, caixa postal 121, Irati (PR), Brasil. afigfilho@gmail.com

Recebido para publicação em 3/06/2013 e aceito em 20/01/2014

Ci. Fl., v. 26, n. 1, jan.-mar., 2016 
age 10, the stands of bracatingastart toshow a configuration of a desne pole stand.

Keywords:diametricdistribution;forest dynamics; Mimosa scabrella,

\section{INTRODUÇÃO}

A bracatinga (Mimosa scabrella Bentham) é uma espécie pioneira, arbórea, de vida curta (vive de 25 a 30 anos) e tem grande importância na Região Metropolitana de Curitiba, Paraná. Ela vem sendo manejada tradicionalmente desde o início do século XX, na forma de densos povoamentos, conhecidos como bracatingais, cuja finalidade é predominantemente a produção de lenha (BAGGIO et al., 1986 e EMBRAPA FLORESTAS, 1988).

O manejo tradicionalmente aplicado consiste no corte raso a cada sete anos, seguido de queima dos resíduos, regeneração natural, plantio de culturas anuais (milho e feijão) no meio da regeneração e abandono da área até a próxima rotação, quando se repete o processo de corte raso, queima, culturas e pousio da área. Esta forma de uso da terra ocupa uma área de 66.768 ha (MAZZA et al., 2000a) na Região Metropolitana de Curitiba e é muito importante para o pequeno agricultor que, tradicionalmente divide sua propriedade em sete partes, colhendo uma das partes por ano. Estes colonos normalmente têm mantido a sustentabilidade deste processo por mais de 100 anos, considerando seus bracatingais como uma poupança verde.

Já se conhece também a utilidade dessa espécie em projetos de recuperação de áreas degradadas, já que após se estabelecer, ela se desenvolve rápido, ocupando e melhorando as condições físicas, químicas e biológicas do terreno, favorecendo o surgimento de outras espécies que vão substituindo-a ao longo do tempo (FERREIRA et al., 2002; REGENSBURGER et al., 2008).

O sub-bosque formado nos bracatingais foi estudado nas idades próximas ao corte, como pode ser observado em Baggio et al. (1995), Baggio \& Carpanezzi (1998) e Mazza et al. (2000b). Porém, esses estudos buscaram agregar valor as outras espécies, já que seriam cortadas juntamente com a bracatinga. Já estudos que ultrapassam a idade de corte desconsideram o sub-bosque, como se observou em Machado et al. (2006), Machado et al. (2008b), Teo et al. (2010a), Teo et al. (2010b), Ribeiro et al. (2012) e Souza et al. (2013),

Dessa forma, observou-se que a evolução do sub-bosque de bracatingais ao longo dos anos ainda é pouco estudada. Steenbock et al. (2011) é uma boa referência. Mesmo assim, os bracatingais estudados por esses autores estão inseridos em um contexto diferente daqueles cultivados na Região Metropolitana de Curitiba, pois seguem o sistema florestal de manejo, enquanto que os de Curitiba são predominantemente agroflorestais.

Em se tratando da evolução estrutural de bracatingais, a mortalidade natural foi avaliada por Machado et al. (2002) e o efeito da densidade sobre a distribuição diamétrica das bracatingas por Machado et al. (2008), porém, ambos abrangeram idades de até 7,5 anos. Portanto, carece ainda ser estudado como se comportam as alturas e os diâmetros ao longo dos anos, até as idades em que a estrutura do sub-bosque supera a da bracatinga.

O comportamento da mortalidade, altura e diâmetros ao longo dos anos podem servir como orientação para se estabelecer novas formas de manejo. Assim, o objetivo deste trabalho foi estudar a estrutura de bracatingais ao longo dos vinte primeiros anos, destacando as alterações em número de indivíduos, diâmetro e altura total das espécies arbóreas que vão surgindo ao longo dos anos.

\section{MATERIAL E MÉTODO}

Esta pesquisa teve como foco os bracatingais da Região Metropolitana de Curitiba (Figura 1). Tais bracatingais são mais recorrentes na porção norte dessa região. Em coordenadas geográficas, a área de estudo é limitada ao norte pela latitude $24^{\circ} 58^{\prime} 11^{\prime \prime} \mathrm{S}$, ao sul pela latitude $25^{\circ} 55^{\prime} 44^{\prime \prime} \mathrm{S}$ ao oeste pela longitude $49^{\circ} 29^{\prime} 09^{\prime} \mathrm{O}$ e ao leste pela longitude $49^{\circ} 03^{\prime} 58^{\prime \prime} \mathrm{O}$. A altitude média é de 950 metros acima do nível do mar.

A área de estudo está localizada no primeiro planalto do Paraná que é recortado por uma paisagem recente de elevações devido aos afluentes do profundo vale do rio Ribeira. O clima nessa região, de acordo com a classificação de Köppen, é o $\mathrm{Cfb}$, com temperatura média anual de $16,5^{\circ} \mathrm{C}$, temperatura do mês mais quente de $20,4^{\circ} \mathrm{C}$ e do mês mais frio de $12,7^{\circ} \mathrm{C}$. O mês mais chuvoso é janeiro, com 190,7 milímetros, já o mês menos chuvoso é o mês de agosto com 78,2 milímetros e a precipitação anual fica em torno de 1.500 milímetros 


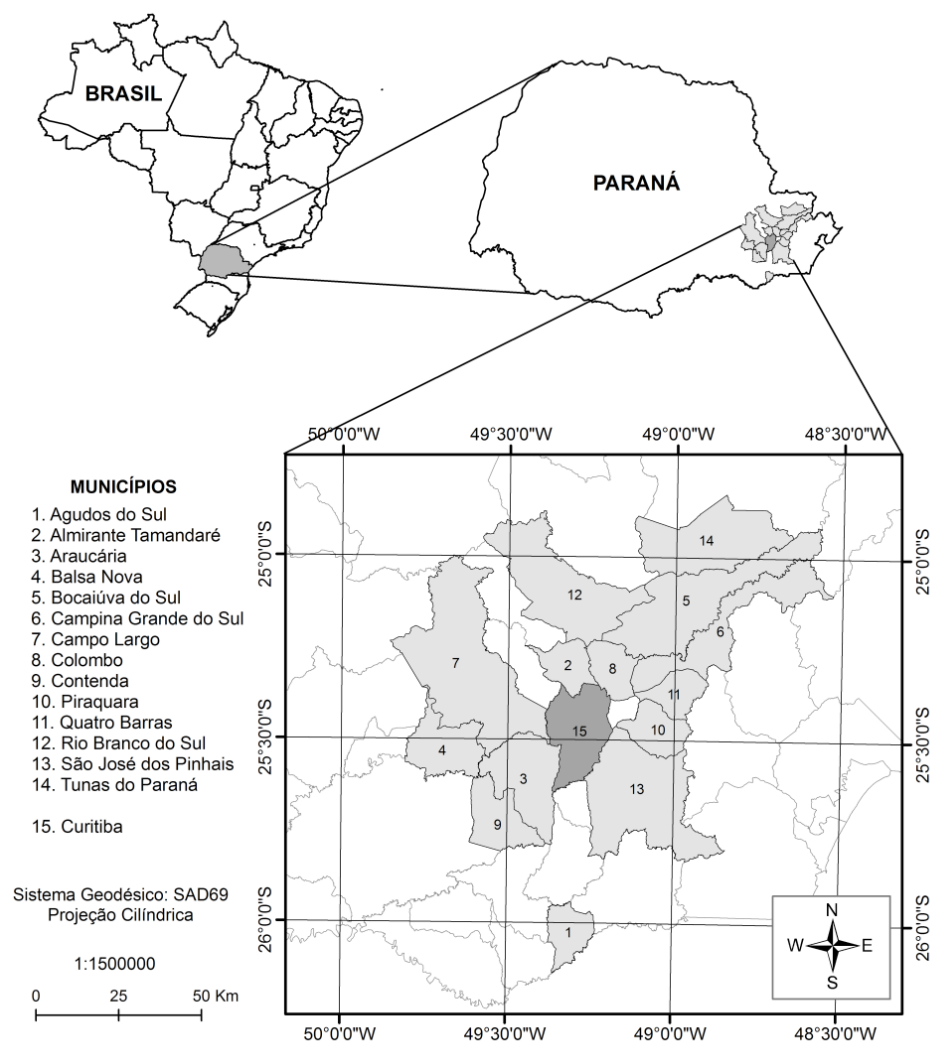

FIGURA 1: Localização dos municípios da Região Metropolitana de Curitiba onde foram amostrados os bracatingais.

FIGURE 1: Location of municipalities in Curitiba Metropolitan Region where bracatinga stands were sampled.

(MAACK, 2002).

Segundo Mineropar(2001), orelevodaregião em que se encontra a maior parte dos bracatingais é acidentado e as rochas predominantes são os filitos, calcários, dolomitos, mármores e quartzitos. Os solos são, na maioria, cambissolos álicos, com diferentes graus de profundidade e fertilidade. Há também os diques de diabásio que cortam as rochas. Devido à grande alterabilidade dos minerais formadores do diabásio, ocorre a formação de grande quantidade de material fino, ou seja, maiores quantidades de argila, o que gera uma condição diferenciada para desenvolvimento da vegetação.

Os dados utilizados na presente pesquisa provieram de 320 parcelas temporárias, instaladas e medidas em bracatingais nativos, com idades variando de 3 a 20 anos, sendo 190 parcelas com área de $300 \mathrm{~m}^{2}(10 \times 30 \mathrm{~m}), 95 \mathrm{com}$ área de $100 \mathrm{~m}^{2}$ $(10 \times 10 \mathrm{~m})$, instaladas em bracatingais mais novos, $31 \mathrm{com} 400 \mathrm{~m}^{2}(10 \times 40 \mathrm{~m})$ e $4 \mathrm{com} 600 \mathrm{~m}^{2}(20 \times 30$ $\mathrm{m})$, nos bracatingais mais velhos.
A idade de cada bracatingal foi fornecida pelo proprietário ou obtida com a derrubada de algumas bracatingas para a contagem in loco dos anéis de crescimento da base ou, em caso de dúvidas, discos eram coletados, secos e lixados para que a contagem dos anéis pudesse ser feita com mais exatidão no laboratório. Quando não era permitido o corte, foram feitas tradagens na altura do DAP e os rolos de incremento foram retirados e, depois de secos, lixados, para facilitar a contagem dos anéis.

Em todas as unidades amostrais foram consideradas apenas as espécies arbóreas cujos indivíduos com diâmetro a $1,30 \mathrm{~m}$ do solo fossem maior ou igual a $5,0 \mathrm{~cm}$, o que equivale à circunferência maior ou igual a $15,7 \mathrm{~cm}$. Tais indivíduos foram identificados em campo por um especialista. Para as espécies duvidosas, foram preparadas exsicatas que foram levadas ao herbário do curso de Engenharia Florestal da Universidade Federal do Paraná em Curitiba - PR, para comparação com as amostras tombadas. De 
cada indivíduo foi medida a circunferência com fita métrica e a altura total, com vara métrica telescópica graduada em centímetro para os indivíduos com até 12 metros e com hipsômetro de Blume-Leiss para aqueles com alturas maiores.

Embora a identificação das outras espécies não tenha sido usada neste estudo, ela foi efetuada para possibilitar a determinação da intensidade amostral adequada. Considerou-se mais importante amostrar os bracatingais em função da diversidade do sub-bosque para melhor comparar sua estrutura com a apresentada pela bracatinga. Dessa forma, as espécies foram divididas apenas em bracatinga e não bracatinga, para que se comparasse a evolução do bracatingal em relação ao sub-bosque como um todo.

Magurran (2011) propôs um procedimento para avaliar a amostragem realizada. Seguindo essa ideia, foi plotado o índice de diversidade de Simpson contra o tamanho amostral cumulativo. A ordem com que as amostras foram incluídas foi aleatorizada 100 vezes. Todo o procedimento foi realizado com o programa EstimateS (http:// viceroy.eeb.uconn.edu/EstimateS) para cada idade amostrada individualmente. Magurran (2011) comenta que o índice de diversidade de Simpson fornece uma estimativa boa e consistente, mesmo usando populações razoavelmente pequenas. Os valores médios da aleatorização das parcelas para o índice de Simpson e os desvios gerados pelo software EstimateS foram exportados para uma planilha eletrônica, na qual foram produzidos os gráficos.

Foi estabelecida a distribuição do número de indivíduos por hectare e a variação do diâmetro máximo médio e altura máxima média, para a bracatinga e para o conjunto das demais espécies ao longo das idades estudadas. Depois para as idades consideradas mais representativas, foi elaborada a distribuição dos diâmetros em classes diamétricas com intervalo de $5 \mathrm{~cm}$, para a bracatinga $\mathrm{e}$ para as demais espécies, a fim de se observar o comportamento da estrutura diamétrica do bracatingal ao longo das idades e estabelecer a idade em que a vegetação deixa de ser um bracatingal.

\section{RESULTADOS E DISCUSSÃO}

A Figura 2 relaciona o índice de riqueza de Simpson, na sua forma inversa $1 / \mathrm{D}$, ao número acumulado de parcelas inventariadas em cada idade dos bracatingais. Se a curva média do índice de diversidade atingir uma assíntota, haverá razoável confiança de que o número de parcelas amostradas foi suficiente, no que se refere à diversidade expressa por este índice. Dessa forma, pode ser constatado que apenas o número de parcelas medidas nos bracatingais com 20 anos de idade não foi suficiente. Isso ocorreu porque foi encontrado apenas um pequeno bracatingal com essa idade, no qual foi possível medir poucas parcelas. $\mathrm{Na}$ área de estudo, os bracatingais com idades a partir dos 15 anos são raros. Geralmente são áreas com algum impedimento para o corte ou que passaram a ser destinadas à preservação, por isso há menos parcelas representando-os. A idade de 19 anos é outro exemplo de bracatingal único, porém, tratavase de uma área grande o suficiente para serem medidas mais parcelas. A idade de três anos não foi incluída porque havia apenas bracatinga com diâmetro superior a $5,0 \mathrm{~cm}$. Assim, para essa idade, o procedimento produziria uma linha reta para qualquer número de parcelas.

Quando determinada idade é amostrada em um único ponto da área de estudo, as condições do sítio daquela região vão influenciar as respostas encontradas e a extrapolação dos resultados para o restante da área de estudo fica prejudicada, já que há grande variação de sítios, que fazem variar também o desenvolvimento da vegetação sobre eles. No caso dos bracatingais já existentes, não há como evitar esse problema, a não ser que se trabalhe com classes de idades, porém, perde-se a oportunidade de observar o que está ocorrendo ano a ano.

Para as idades abaixo de 15 anos, menos parcelas já seriam suficientes, principalmente para as idades de 4 a 10 anos, nas quais a curva se manteve constante, independentemente do número de parcelas amostradas. Isso ocorreu porque o índice de diversidade é dependente do número de espécies e da proporção de cada espécie no número total de indivíduos presentes em determinada idade. Como o número de bracatingas é superior ao de qualquer outra espécie, até os 10 anos, mesmo que haja várias outras espécies em cada idade, por serem de número muito menor, a contribuição delas para a composição do índice é pequena demais para causar alteração na curva média e o que se vê é praticamente uma reta, independentemente da quantidade de parcelas medidas. Em outras palavras, até os 10 anos de idade, um bracatingal é praticamente um povoamento de uma única espécie (bracatinga), assim com poucas parcelas já se teria uma amostragem suficiente da diversidade. Então, de forma geral, a amostragem 

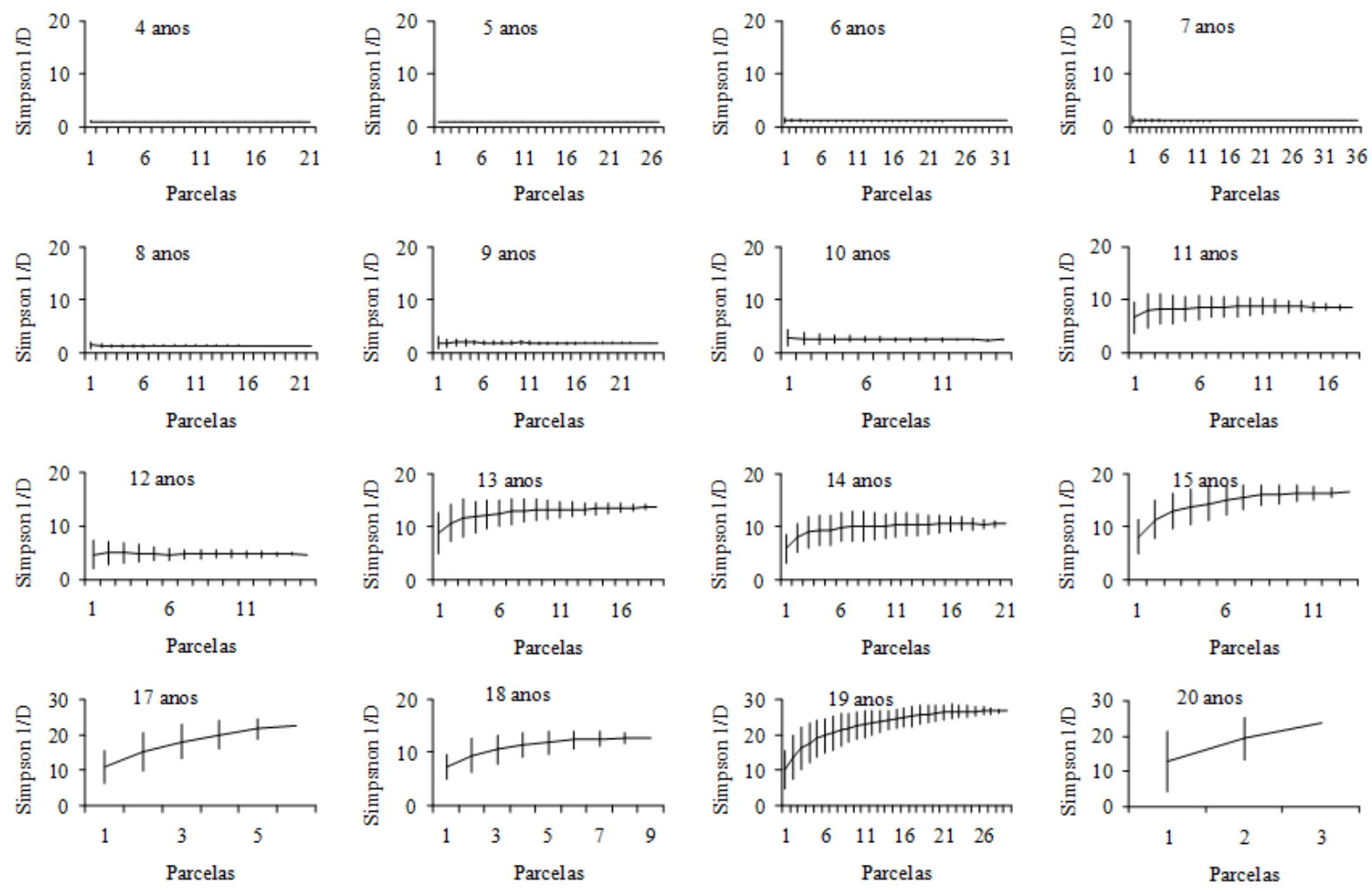

FIGURA 2: Comportamento do índice de Simpson (como 1/d \pm 1 desvio padrão) em relação ao número de parcelas amostradas, com 100 diferentes aleatorizações, para as diferentes idades dos bracatingais.

FIGURE 2: Behavior of Simpson index (as $1 / \mathrm{d} \pm 1$ standard deviation) in relation to the number of sampled plots, with 100 randomizations, for different ages of bracatinga stands.

efetuada nas diferentes idades dos bracatingais oferece certa segurança para as afirmações feitas no presente trabalho.

Devido ao banco de sementes, o número de indivíduos da bracatinga que germinam espontaneamente após a queima do terreno chega a 100.000 por hectare. Os produtores costumam ralear o bracatingal cerca de um ano depois, de forma a deixar aproximadamente 25.000 indivíduos por hectare. Após esta intervenção, a área é abandonada e a competição e a mortalidade naturais reduzem o número de indivíduos de bracatinga (Figura 3). Essa redução pode ser representada pelo modelo matemático exponencial de Meyer tipo II, com os coeficientes já ajustados, o erro padrão da estimativa percentual $\left(\mathrm{s}_{\mathrm{yx}(\%)}\right)$ e o índice de Schlaegel (IA). O IA é uma alternativa ao coeficiente de determinação $\left(\mathrm{R}^{2}\right)$ e seu valor de 0,96 indica que a variação da idade explica $96 \%$ da variação do número de árvores de bracatinga. O modelo tipo I de Meyer também foi ajustado, porém, a forma como esse modelo foi estruturado por Meyer resultou em um erro $\left(\mathrm{s}_{\mathrm{yx}(\%)}\right)$ superior a $27 \%$. Estudos já evidenciaram essa alta densidade inicial e a intensa mortalidade natural ao longo dos anos, como Machado et al. (2002) e Machado et al. (2008a).

Considerando apenas o conjunto das demais espécies de um bracatingal, verifica-se que a situação para elas é muito diferente. Elas estão ausentes aos 3 anos de idade, porém, aos 4 anos já há certo número de indivíduos, embora muito pequeno quando comparado ao da bracatinga, como pode ser observado na Figura 2. À medida que o tempo passa, o número de indivíduos de outras espécies vai aumentando até ultrapassar o número de bracatinga, por volta dos 11 anos de idade. Já aos 19 anos, podese dizer que a situação é oposta e a bracatinga é que passa a ser pouco expressiva, contudo, o conjunto das outras espécies não atinge o mesmo número de indivíduos da bracatinga nos primeiros anos. 


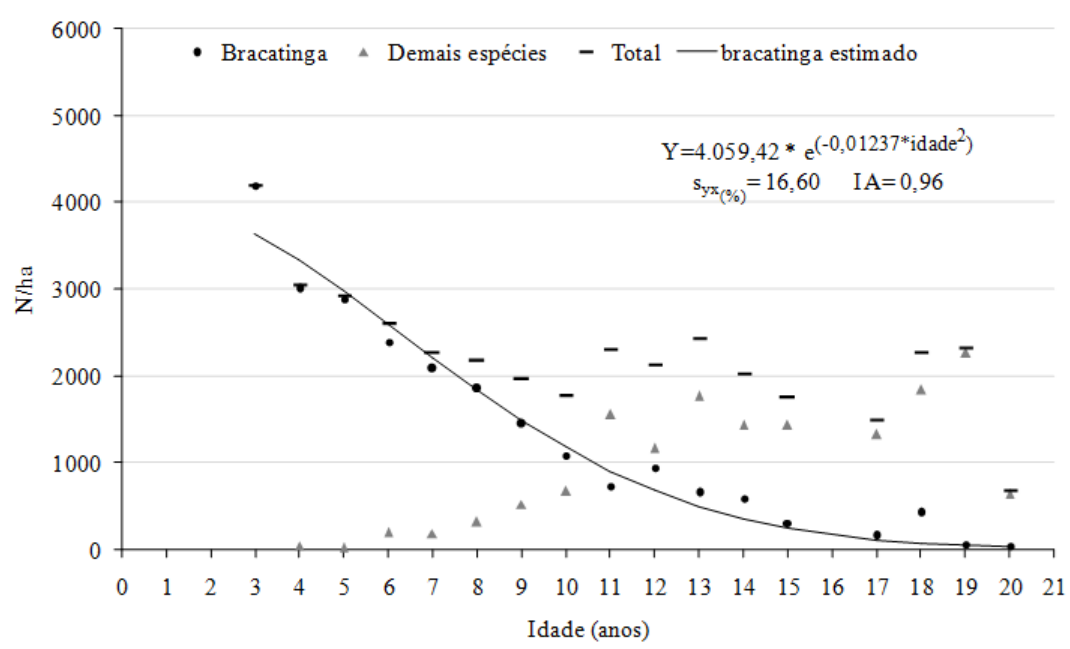

FIGURA 3: Comportamento do número de árvores por hectare da bracatinga e das demais espécies ao longo dos anos, considerando um diâmetro mínimo de $5 \mathrm{~cm}$.

FIGURE 3: Behavior of the number of trees per hectare of bracatinga and of other species over the years, considering a minimum diameter of $5 \mathrm{~cm}$.

Isso significa que não há uma única espécie com número de indivíduos muito superior às demais, a situação está mais equilibrada, com várias espécies apresentando um número significante de indivíduos, o que confere ao bracatingal uma condição melhor de equabilidade, aproximando-o de uma vegetação em estágio mais avançado de desenvolvimento. Obviamente, essa mudança ao longo do tempo é um reflexo não apenas da mudança do número de indivíduos, mas também de mudanças no porte que esses indivíduos apresentam, como pode ser observado na Tabela 1.

Aos 3 anos de idade há apenas indivíduos de bracatinga com DAP maior ou igual a $5 \mathrm{~cm}$. A partir dos 4 anos, outras espécies vão surgindo, ao passo que a proporção de bracatingas em relação ao total vai reduzindo. Aos 7 anos, idade preferida para o corte dos bracatingais, o número de bracatingas chega a $91 \%$ do total de indivíduos, apesar de já haver a presença de mais 32 espécies. Essas demais espécies, embora em número muito menor, já apresentam indivíduos com diâmetros próximos da média das bracatingas. O período com maior diversidade foi entre os 13 e 14 anos, embora a partir dos 11 ou 12 anos o número de espécies nos bracatingais seja bastante elevado e o número de bracatingas inferior a $45 \%$. A idade de 20 anos não foi considerada já que a amostragem foi insuficiente.

De forma geral, se o bracatingal não for cortado aos 7 anos, as bracatingas vão morrendo naturalmente, como já demonstraram Machado et al. (2002), e outras espécies vão se instalando e se desenvolvendo, porém, o desenvolvimento do conjunto das demais espécies é mais lento que o da bracatinga. Nos primeiros anos percebe-se que o DAP mínimo dos indivíduos de bracatinga ficou próximo dos $5 \mathrm{~cm}$ porque esse era o valor mínimo de inclusão e, conforme o bracatingal foi envelhecendo e as bracatingas morrendo, o diâmetro mínimo dos indivíduos que ficaram aumentou. Já para o conjunto das demais espécies, esse valor permaneceu próximo aos $5 \mathrm{~cm}$ em praticamente todos os anos, em consequência do recrutamento, ao passo que o diâmetro máximo foi se aproximando do apresentado pela bracatinga, até ultrapassá-lo aos 17 anos. A partir daí, a idade de 18 anos foi a única que voltou a apresentar um diâmetro máximo para a bracatinga superior ao das demais espécies. Atribui-se isso ao fato de se trabalhar com um único sítio para as idades de 18, 19 e 20 anos. O sítio com 18 anos era mais favorável à bracatinga, tanto que a porcentagem de bracatingas (\%brac), que vinha em uma tendência forte de queda, sofreu um bom aumento. Já o sítio com 19 anos era ruim tanto para a bracatinga, quanto para as demais espécies, já que o diâmetro máximo ficou abaixo da tendência que vinha apresentando. Isso mostra que, a partir dos 17 anos, as demais espécies que vinham se desenvolvendo no sub-bosque do bracatingal já começam a dominar efetivamente a área, apesar de já serem mais numerosas que a bracatinga desde os 11 anos. A variação dos sítios é que dificulta estabelecer 
TABELA 1: Comportamento dos diâmetros (DAP) e alturas totais (HT) da bracatinga e das espécies encontradas em bracatingais ao longo do tempo.

TABLE 1: Behavior of diameter (DBH) and total height (HT) of bracatinga and other species found in bracatinga stands over the time.

\begin{tabular}{|c|c|c|c|c|c|c|c|c|c|c|c|c|c|c|}
\hline \multirow{3}{*}{ Idade } & \multirow{3}{*}{$\begin{array}{l}\text { N. } \\
\text { esp. }\end{array}$} & \multirow{3}{*}{$\begin{array}{c}\% \\
\text { brac. }\end{array}$} & \multicolumn{6}{|c|}{ Bracatinga } & \multicolumn{6}{|c|}{ Demais Espécies } \\
\hline & & & $\begin{array}{c}\text { DAP } \\
\text { min }\end{array}$ & $\begin{array}{l}\text { DAP } \\
\text { med }\end{array}$ & $\begin{array}{l}\text { DAP } \\
\max \end{array}$ & $\begin{array}{l}\mathrm{HT} \\
\mathrm{min}\end{array}$ & $\begin{array}{l}\text { HT } \\
\text { med }\end{array}$ & $\begin{array}{l}\text { HT } \\
\max \end{array}$ & $\begin{array}{l}\text { DAP } \\
\text { min }\end{array}$ & $\begin{array}{l}\text { DAP } \\
\text { med }\end{array}$ & $\begin{array}{l}\text { DAP } \\
\text { max }\end{array}$ & $\begin{array}{l}\mathrm{HT} \\
\mathrm{min}\end{array}$ & $\begin{array}{l}\text { HT } \\
\text { med }\end{array}$ & $\begin{array}{l}\text { HT } \\
\max \end{array}$ \\
\hline & & & $(\mathrm{cm})$ & $(\mathrm{cm})$ & $(\mathrm{cm})$ & $(\mathrm{m})$ & $(\mathrm{m})$ & $(\mathrm{m})$ & $(\mathrm{cm})$ & $(\mathrm{cm})$ & $(\mathrm{cm})$ & $(\mathrm{m})$ & (m) & $(\mathrm{m})$ \\
\hline 3 & 1 & 100 & 5,1 & 7,0 & 11,3 & 7,3 & 9,9 & 11,6 & - & - & - & - & - & - \\
\hline 4 & 9 & 98 & 5,0 & 7,0 & 12,6 & 7,0 & 9,6 & 11,8 & 5,1 & 5,4 & 6,2 & 6,8 & 7,3 & 8,0 \\
\hline 5 & 8 & 99 & 5,1 & 7,1 & 12,5 & 7,0 & 9,9 & 12,5 & 5,6 & 5,8 & 6,3 & 5,6 & 6,2 & 6,8 \\
\hline 6 & 31 & 92 & 5,1 & 8,1 & 14,1 & 8,4 & 11,2 & 13,9 & 5,0 & 5,7 & 7,2 & 5,0 & 6,3 & 7,7 \\
\hline 7 & 33 & 91 & 5,4 & 8,4 & 15,3 & 7,7 & 10,6 & 13,3 & 5,4 & 5,9 & 7,2 & 5,4 & 6,4 & 7,7 \\
\hline 8 & 34 & 83 & 5,4 & 9,4 & 16,5 & 7,7 & 11,9 & 15,2 & 5,3 & 6,9 & 10,1 & 5,0 & 6,8 & 9,0 \\
\hline 9 & 45 & 71 & 6,1 & 10,5 & 18,5 & 9,0 & 13,7 & 17,0 & 5,2 & 6,1 & 8,3 & 4,2 & 6,2 & 8,5 \\
\hline 10 & 43 & 61 & 6,1 & 11,1 & 18,7 & 8,6 & 13,5 & 17,0 & 5,2 & 6,9 & 11,3 & 4,4 & 7,2 & 10,3 \\
\hline 11 & 68 & 31 & 6,9 & 11,9 & 19,9 & 9,3 & 13,5 & 16,9 & 5,1 & 6,9 & 13,6 & 3,1 & 6,2 & 10,9 \\
\hline 12 & 64 & 44 & 6,4 & 12,1 & 19,9 & 10,1 & 13,8 & 17,4 & 5,0 & 6,2 & 10,9 & 4,6 & 6,9 & 9,8 \\
\hline 13 & 93 & 24 & 8,5 & 14,2 & 22,7 & 10,7 & 14,6 & 17,6 & 5,0 & 7,0 & 14,0 & 3,6 & 6,7 & 12,3 \\
\hline 14 & 94 & 28 & 8,2 & 12,9 & 21,4 & 9,8 & 13,3 & 16,6 & 5,1 & 7,2 & 14,1 & 3,3 & 6,5 & 10,8 \\
\hline 15 & 77 & 18 & 10,5 & 16,8 & 24,8 & 12,0 & 15,2 & 18,0 & 5,1 & 8,9 & 20,5 & 3,5 & 7,9 & 13,5 \\
\hline 17 & 67 & 12 & 13,3 & 17,0 & 23,6 & 11,4 & 13,6 & 16,2 & 6,8 & 11,5 & 28,4 & 5,2 & 9,1 & 14,3 \\
\hline 18 & 52 & 18 & 10,8 & 18,8 & 28,7 & 12,0 & 15,9 & 19,7 & 5,0 & 7,6 & 15,1 & 4,1 & 7,6 & 12,3 \\
\hline 19 & 72 & 3 & 12,7 & 13,9 & 17,3 & 9,0 & 10,0 & 11,1 & 5,2 & 9,6 & 24,5 & 2,7 & 5,7 & 10,1 \\
\hline
\end{tabular}

Em que N. esp. $=$ número de espécies, \%brac. = porcentagem de bracatingas em relação ao número total de indivíduos, $\mathrm{DAP}=$ diâmetro a $1,30 \mathrm{~m}$ do solo, $\mathrm{HT}=$ altura total, $\mathrm{min}=$ mínimo, med $=$ médio, Max $=$ máximo.

a idade em que se pode afirmar que os diâmetros de outras espécies superarão o da bracatinga. O fato é que isso foi observado aos 17 anos e, obviamente, a oscilação de diâmetros máximos após os 17 anos indica que essa mudança não é abrupta, podendo ocorrer bracatingais com idades superiores a essa, em que as demais espécies ainda não alcançaram a bracatinga em diâmetro máximo.

Em relação às alturas totais, a situação parece estar mais bem definida. A bracatinga cresce até aos 9 anos e depois com forte tendência à estagnação. Os bracatingais não passaram dos 20 metros de altura e, até os 19 anos, as demais espécies não atingiram o máximo em altura, alcançado pela bracatinga. As alturas máximas do conjunto das demais espécies evoluíram próximo às alturas mínimas da bracatinga, até que, dos 19 anos em diante, elas passaram a ocupar o ponto mais alto do estrato que antes era exclusivo da bracatinga. Ao se observar o comportamento do número de bracatingas em relação ao número total de indivíduos (\%brac), percebe-se que, à medida que a bracatinga vai morrendo, os indivíduos remanescentes só deixam de apresentar os valores mais altos de DAP e HT quando seu número é reduzido para menos de $10 \%$ do total, o que ocorre dos 19 anos em diante. Essa inversão de domínio da bracatinga para as demais espécies fica bem evidenciada na distribuição dos diâmetros em classes (Figura 4). No período de 4 a 7 anos, quase que a totalidade dos indivíduos tem, no máximo, $10 \mathrm{~cm}$ de DAP. Dos 7 aos 19 anos, uma porção considerável dos indivíduos alcança a classe de 10 a $15 \mathrm{~cm}$. As bracatingas (A) raramente ultrapassam os $20 \mathrm{~cm}$ de DAP, em qualquer idade, já as demais espécies (B) apresentaram indivíduos com mais de $20 \mathrm{~cm}$ de DAP apenas aos 19 anos. 


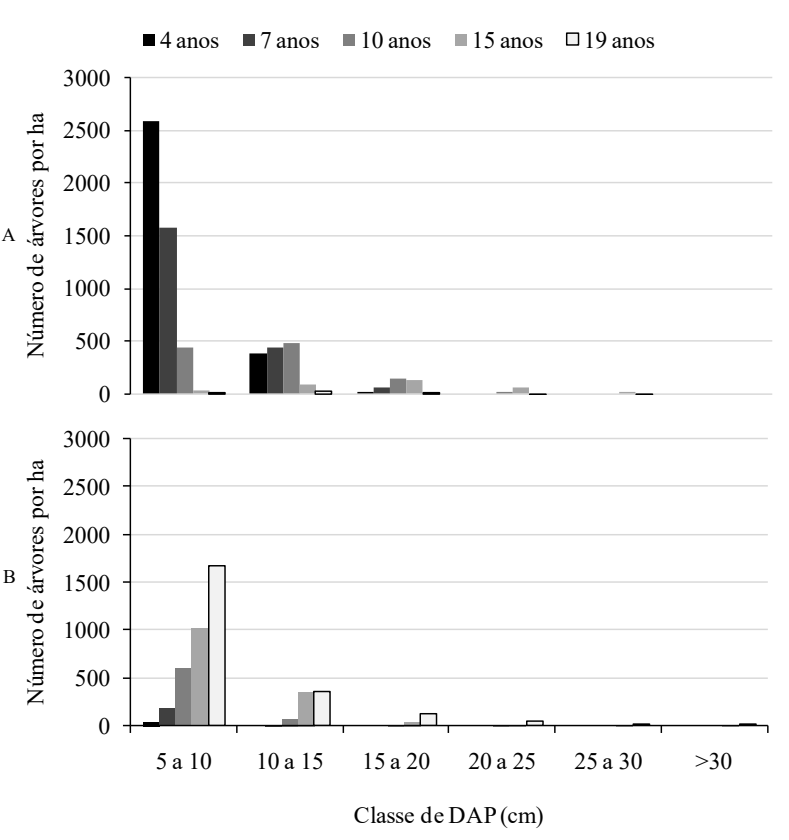

FIGURA 4: Distribuição diamétrica da bracatinga (A) e das demais espécies (B) ao longo dos anos, em bracatingais da Região Metropolitana de Curitiba, Paraná.

FIGURE 4: Diameter distribution of bracatinga (A) and other species (B) over the years in the Metropolitan Region of Curitiba, State of Paraná.

Na primeira classe de diâmetro (5 a 10 $\mathrm{cm}$ ), considerando o período de 4 a 19 anos, houve forte queda no número de indivíduos de bracatinga e o gradual aumento do número de indivíduos das demais espécies, sendo a idade de 10 anos o momento em que essas espécies superaram a bracatinga no domínio da classe. Já para a segunda classe (10 a $15 \mathrm{~cm}$ ), apenas aos 15 anos as demais espécies ocorreram em maior número que a bracatinga e, para diâmetros superiores a $15 \mathrm{~cm}$, as demais espécies só superam a bracatinga dos 19 anos em diante. Além disso, na idade de 19 anos, quando a bracatinga não é mais expressiva, o conjunto das demais espécies apresenta uma distribuição com um formato semelhante ao de uma floresta em estágio de desenvolvimento mais avançado.

Assim, entende-se que as principais mudanças nos bracatingais ocorrem entre 10 e 11 anos de idade, quando o número de indivíduos do conjunto das demais espécies ultrapassa o número de bracatingas e passam a ser a maioria também na classe de diâmetro de 5 a $10 \mathrm{~cm}$. Dessa forma, considerando apenas o número de indivíduos, as mudanças indicam que, a partir dos 10 anos de idade, a vegetação passa a ter uma configuração diferente daquela típica de um bracatingal, com finalidade para a produção de lenha, na qual a bracatinga domina em número de indivíduos $\mathrm{e}$ porte. Assim, pode-se dizer que, a partir dos 10 anos, o nome capoeirão passa a ser mais adequado que bracatingal.

\section{CONCLUSÕES}

Aos 11 anos, o conjunto das demais espécies supera a bracatinga em número de indivíduos por hectare;

Aos 19 anos, a bracatinga tem pouca representatividade na distribuição diamétrica do bracatingal;

Aos 19 anos, as demais espécies já apresentam distribuição diamétrica semelhante à de uma formação em estágio mais avançado (capoeirão).

\section{REFERÊNCIAS BIBLIOGRÁFICAS}

BAGGIO, A. J.etal.Sistema agroflorestal tradicional da bracatinga com culturas agrícolas anuais.Boletim de Pesquisa Florestal, Colombo, n. 12, p. 73-82, jun., 1986.

BAGGIO, A. J.et al. Levantamento de espécies lenhosas em sub-bosque de bracatingais. Boletim de Pesquisa Florestal. Colombo: Embrapa Florestas, n. 30/31, p. 69-74, jan./dez., 1995.

BAGGIO, A. J.; CARPANEZZI, A. A. Exploração seletiva do sub-bosque: uma alternativa para aumentar a rentabilidade dos bracatingais. Colombo: Embrapa Florestas, 1998. 17 p. (Circular Técnica, 28).

EMBRAPA FLORESTAS. Centro Nacional de Pesquisa de Florestas, Curitiba, PR. Manual técnico da bracatinga (Mimosa scabrellaBenth), por Antonio Aparecido Carpanezzi e outros. Curitiba, 1988, 70p. (EMBRAPA. CNPF. Documentos, 20).

FERREIRA, C.A. G.; TAUK-TORNISIELO, S. M.; CHAVES, M. M. F. Comportamento de bracatinga (Mimosa scabrella) esebastiânia(Sebastianiasesban) em áreas degradadas pela deposição de resíduos provenientes do processamento da bauxita. Holos Environment, v. 2, n. 2, p. 156-173, 2002.

MAACK, R. Geografia física do estado do Paraná. 3. ed. Curitiba: Imprensa Oficial do Paraná, 2002. $440 \mathrm{p}$.

MACHADO, S. do A.et al. Evolução da área basal e do volume em bracatingais nativos submetidos a 
diferentes densidades iniciais e em diferentes sítios. Floresta, Curitiba, v. 32, n. 1, p. 61-74, 2002

MACHADO, S. A. et al. Relações quantitativas entre variáveis dendrométricas e teores de carbono para Mimosa scabrella Bentham da Região Metropolitana de Curitiba. Pesquisa Florestal Brasileira, Colombo, v. 52, p. 37-60, 2006 MACHADO, S. do A.et al. Efeito da densidade e do sítio sobre as curvas de distribuição diamétrica em bracatingais nativos (Mimosa scabrellaBenth.) da região metropolitana de Curitiba. Ambiência, Guarapuava, v. 4, n. 1, p. 37-50, Jan./Abr., 2008a.

MACHADO, S. Do A. et al. Modelagem volumétrica para bracatinga (Mimosa scabrella) em povoamentos da Região Metropolitana de Curitiba. Pesquisa Florestal Brasileira, Colombo, v. 56, p. 17-29, 2008b.

MAGURRAN, A. E. Medindo a diversidadebiológica. VIANNA, D. M. (trad.). Curitiba: UFPR, 2011, $261 \mathrm{p}$.

MAZZA, C.AdaS.;BAGGIO,A.J.;CARPANEZZI, A. A. 2000a. Distribuição espacial da bracatinga na região metropolitana de Curitiba com imagens de satélite Landsat. Colombo: Embrapa Florestas, 22 p. (Circular técnica, 36)

MAZZA, M.C.M. et al. Potencial de aproveitamento medicinal de espécies do sub-bosque dos bracatingais da região de Curitiba, PR. Colombo: Embrapa Florestas, 2000b. 27p. (Embrapa Florestas.
Documentos, 43).

MINEROPAR (Minerais do Paraná AS) - Serviço Geológico do Paraná: Atlas comentado da geologia e dos recursos minerais do estado do Paraná, 2001, 125p.

REGENSBURGER, B.; COMIN, J. J.; AUMOND, J. Integração de técnicas de solo, plantas e animais para recuperar áreas degradadas.Ciência Rural, Santa Maria, v. 38, n.6, p. 1773-1776, Sept., 2008. RIBEIRO, A. et al. Quantificação e modelagem dos macronutrientes em povoamentos de bracatinga. Pesquisa Florestal Brasileira, Colombo, v. 32, p. 29-44, 2012.

SOUZA, R. F. de et al. Modelagem do carbono orgânico total e da linha por unidade de área para bracatingais nativos. Ciência Florestal, Santa Maria, v. 23, n. 1, p. 117-127, 2013

STEENBOCK, W. et al. Ocorrência da bracatinga (Mimosa scabrellaBenth.) em bracatingais manejados e em florestas secundárias na região do planalto catarinense. Revista Árvore, Viçosa, v. 35, n. 4, Viçosa, Jul/Aug, 2011.

TÉO, S.J. ; et al. Concentração e conteúdo de macronutrientes da biomassa de Mimosa scabrellaBentham, em diferentes classes de sítio, idade e diâmetro. Scientia, v. 11, p. 459-467, 2010a. TÉO, S. J. et al. Micronutrientes da biomassa aérea de bracatinga sob diferentes classes de sítio, idade e diâmetro. Floresta, Curitiba, v. 40, p. 861-870, 2010 b. 